answer to a particular question as at improving the powers of the recipient to extend the bounds of knowledge. Bursaries will be tenable usually for periods of two to twelve months, and holders will not be permitted to prepare specifically for, or to take examinations for, higher degrees or diplomas. Forms of application must reach the Assistant Secretary, Royal Society, Burlington House, London, W.1, before March 15 each year for proposed visits beginning in July of the same year or later, and before September 15 each year for proposed visits beginning in January of the following year or later.

Some Aspects of the Conflict between Science and Religion

For the Seventh Arthur Stanley Eddington Memorial Lecture, delivered on November 3, Prof. H. H. Price, Wykeham professor of logic in the University of Oxford, spoke on "Some Aspects of the Conflict between Science and Religion". In this Lecture, now published (pp. 54 ; Cambridge: University Press, $1953 ; 3 s .6 d$.$) , Prof. Price argues that of late$ the main conflict between science and religion has been over two opposed conceptions of human personality; a materialist and a dualist one. On one side, it is held that all mental processes are produced by and inseparable from bodily processes, or else actually are bodily. According to the religious conception, on the other side, some kind of cognition of the divine is possible, which cannot be supposed to have any ordinary physiological correlates, and also some kind of other-worldly existence distinct from the present bodily one. The systematic investigation of the phenomena of para-normal cognition, such as telepathy, clairvoyance and precognition, has made the materialist conception far less plausible, if not untenable. A dualist type of theory, which does not exclude the theistic and other-worldly view, can no longer be dismissed as unscientific and superstitious. Prof. Price apologizes for dealing with the conflict between science and religion in commemoration of Eddington, for whom there was no conflict. No apology is needed for this masterpiece of cautious, precise and convincing statement.

\section{Wheat Leaf Invertase}

IN an investigation of the invertase in the first leaf of wheat, D. W. A. Roberts (Canad. J. Bot., $31,4,367 ; 1953$ ) obtained no evidence that the enzyme consists of a phosphorylase and a phosphatase. Solid preparations of the enzyme were obtained by precipitating it with ammonium sulphate from suitably prepared wheat leaf juice. Studies of the distribution of this enzyme in the first leaf of wheat shows that it reaches its maximum concentration at the close of the period of elongation and that it is most abundant in the basal regionan indication that the enzyme may be more closely associated with the vascular tissue than with the chlorenchyma.

\section{Transformers Wound without Wire}

AN interesting development in the field of telecommunications is a special transformer of small dimensions and wound without wire, which has been designed at the Bell Telephone Laboratories for use in the amplifying units of carrier systems working on coaxial cable. The outer and inner formers consist of thin-walled cylinders, about the size of cotton reels, of 'Vicor' glass, a borosilicate glass, chosen because of its stability and resistance to physical change. They are ground so that they have accurately constant (to within $10^{-4} \mathrm{in}$.) diameters, and threads are then cut with $\varepsilon_{0}$ diamond wheel into the cylinders. A coating of powdered silver and ground glass is sprayed on, and copper is then electroplated on to the formers. The excess copper is removed, and fine and exact wire coils consisting of the copper in the grooves are obtained. The threads are cut in an unusual form so that the coils ultimately obtained can neither expand nor shrink. Such transformers are being manufactured by the Western Electric Company.

\section{Yokohama Mathematical Journal}

THE Department of Mathematics of Yokohama Municipal University has started to publish the Yokohama Mathematical Journal, edited by T. Takasu with the co-operation of other members of the staff of the Department. The first number is dated May 1953 (pp. 130) and contains ten papers, each of which is of considerable interest. Eight of the papers are by the editor, and form a connected series ; starting with a general theory of connexion spaces in the large, he develops this to apply to relativity, quantum mechanics, and a combined field theory. So far, all the papers printed or announced for subsequent numbers are by members of the editorial board. 'The Journal will be published twice a year, the two issues forming a volume; its price is not stated. All correspondence should be addressed to the editor at the Department of Mathematics, Yokohama Municipal University, Kanazawa-Hakkei, Yokohama.

Transactions of the Dublin Soils Conference, 1952

BoTH volumes of the transactions of the joint meeting of Commissions 2 (Soil Chemistry) and 4 (Soil Fertility and Plant Nutrition) of the International Society of Soil Science, held in Dublin during July 1952 under the presidency of Prof. F. Steenbjerg, have now been published (Vol. 1, pp. 335 ; Vol. 2, pp. 404. Dublin: Department of Agriculture, 1953. £6 the set). The meeting was organized into three sections, dealing respectively with laboratory tochnique for assessing nutrient status of soils; plant and field technique for the evaluation of soil fertility; and correlation and general inquiry. Each of the sessions was opened by a major review paper and two supporting papers; these form the contents of Vol. 1. The remaining contributions, together with the discussion, have been published in Vol. 2, which also contains the official addresses of welcome by the Minister of Agriculture, Mr. T. Walsh, and by Dr. M. Tierney, president of University College, Dublin, and the introductory lecture by Dr. E. M. Crowther, deputy director of Rothamsted Experimental Station. The papers cover a wide field and will be of interest to both chemists and biologists, since the underlying theme is the interpretation of analytical results in terms of increased crop production.

Philosophy of Science Group of the British Society for the History of Science

A Northern Section of the Philosophy of Science Group of the British Society for the History of Science is being formed, and an inaugural meeting will be held in the main building of the University of Manchester on January 30, at 2.30 p.m. Its purpose will be the same as that of the main Group, namely, "to study the logic and method of science as well as of the various special sciences, including the social sciences. The main emphasis is upon an 